\title{
Direitos humanos e democracia na educação infantil: atuação do psicólogo escolar em uma associação pró-educação
}

\author{
Julia Chamusca Chagas \\ Regina Lúcia Sucupira Pedroza \\ Angela Uchoa Branco \\ Universidade de Brasília
}

\begin{abstract}
Resumo
A educação em/para os Direitos Humanos demanda a discussão do papel da escola na formação para a cidadania. Essa formação deve considerar a necessidade do ideal de democracia estar em todos os níveis do contexto escolar, da proposta pedagógica à organização político-administrativa. Nesta pesquisa utilizamos o conhecimento adquirido por uma experiência de atuação em psicologia escolar em uma instituição de Educação Infantil de Brasília que é uma associação de pais, professores e funcionários. O objetivo foi discutir como o psicólogo escolar participava da implementação da noção de democracia no cotidiano da escola e auxiliava a construção da coerência entre o projeto político pedagógico e as práticas educacionais voltadas para a criança. A análise dessa experiência mostrou a importância da psicologia na construção de uma educação para a democracia que trabalhe junto aos educandos não apenas o conhecimento de seus direitos, mas a aprendizagem e o desenvolvimento de práticas cidadãs.
\end{abstract}

Palavras-chave: psicologia escolar; educação infantil; democracia; direitos humanos.

\begin{abstract}
Human rights and democracy in children's education: the role of the school psychologist at a pro-education association. The issue of Human Rights education demands a discussion about the role of the school in developing student citizenship. This process should consider the need for the ideal of democracy to be in every level of the school context; from the pedagogical proposal to its administrative and political organization. In this research we used the knowledge obtained through an experience with school psychology at a children's education institution in Brasília that is an association of parents, teachers and employees. The goal is to discuss how the school psychologist participated in implementing the notion of democracy into the school's routine, helped building coherence between the political and pedagogical project, in addition to the educational practices involving the children. The analysis showed how important psychology is in developing a democratic education that focuses not only on teaching the students their rights, but also on learning and developing practices of citizenship.
\end{abstract}

Keywords: school psychology; children's education; democracy; human rights.

A educação em/para os Direitos Humanos tem sido uma questão muito presente atualmente na elaboração de estudos e políticas públicas de educação. Nesse contexto, surge como questão extremamente relevante a formação para a cidadania e a convivência na diversidade (Candau, 2008). Entretanto, conforme nos alerta Perrenoud (2004), existe uma incoerência constante nas escolas entre a proposta de educação para a cidadania e a sua prática cotidiana. Muitas vezes, as escolas acabam por produzir uma educação moral impositiva, em que as questões éticas e morais não são co-construídas pelos professores junto aos alunos no dia-a-dia de sala de aula, mas sim através de projetos isolados em que um tipo de moral é imposto aos educandos a partir apenas das escolhas, desejos e objetivos dos professores. Dessa forma, Perrenoud (2004) aponta para a necessidade da implementação do ideal de democracia em sala de aula a fim de realizar uma educação para a cidadania.

Neste trabalho, a intenção é ir além da crítica de Perrenoud, mais focada na relação professor-aluno, e trazer as contribuições atuais da educação em/para direitos humanos (Candau, 2008; Carvalho, Sesti, Andrade, Santos, \& Tibério, 2004) para refletir sobre a necessidade de o ideal de democracia estar em todos os níveis do contexto escolar, criando uma coerência entre proposta pedagógica e política. Para isso, foi utilizado o conhecimento adquirido por uma experiência de trabalho como psicóloga escolar em uma instituição de educação infantil no Plano Piloto (DF) que adota uma estrutura político-administrativa muito peculiar para uma escola, a associativa. O que se objetiva discutir é como, a partir da necessidade de coerência entre o projeto 
político pedagógico e as práticas educacionais voltadas para a criança, é trabalhada a noção de democracia em uma escola que é uma Associação Pró-educação.

\section{Perspectiva sociocultural construtivista do desen- volvimento humano}

A perspectiva sociocultural construtivista apresenta uma compreensão dos processos de desenvolvimento humano de forma dinâmica, situados em seu contexto sociocultural. Assim, concebe como o sujeito participa ativamente do seu processo de desenvolvimento e socialização, em contínua interação com os indivíduos e o contexto em que se insere, por meio de processos de construção semióticos (Madureira \& Branco, 2005; Valsiner, 1998).

A dicotomia indivíduo-sociedade é questionada nessa abordagem pelo conceito de separação inclusiva. Esse conceito se baseia na simultaneidade entre a interdependência e a diferenciação entre a pessoa e o seu contexto social no processo de desenvolvimento humano. Isso significa que o desenvolvimento não se reduz a uma influência unilateral nem do organismo, nem do ambiente, mas sim advém da relação de interdependência mútua constituída entre eles. É essa tensão da simultaneidade que promove o jogo dialético do conceito de separação inclusiva (Palmieri \& Branco, 2004; Valsiner, 1989).

Essa compreensão está fundamentada em alguns conceitos básicos da abordagem sociocultural construtivista. A organização temporal é considerada requisito para uma visão de desenvolvimento processual, junto com a percepção das novidades que cada momento traz. Essa perspectiva histórica, porém, deve ser contextualizada em relação ao ambiente, uma vez que é na interação com este que os seres humanos encontram novos desafios e, assim, tanto indivíduo quanto sociedade, passam por transformações estruturais (Valsiner, 1989). Dessa ênfase na dimensão do tempo e de sua irreversibilidade e da contínua interação do sujeito com o contexto sociocultural, deriva a definição de desenvolvimento humano como "um modelo aberto, que contempla a natureza dinâmica, plural, complexa e co-construída do desenvolvimento" (Martins \& Branco, 2001, p.170). Assim, existe sempre a possibilidade de emergência do novo, inesperado e imprevisível (Valsiner, 1989).

Entretanto, um dos pressupostos dessa abordagem é que o desenvolvimento humano não é nem completamente determinável, nem completamente aberto (Barreto, 2004). É necessário considerar que existe uma indeterminação limitada, que garante um movimento constante e dialético do processo designado como canalização cultural, e a possibilidade do indivíduo transformar ativamente as mensagens e sugestões sociais (Branco, 2003). A comunicação e os processos de significação tornam-se, assim, centrais para a compreensão do desenvolvimento humano.

O conceito de canalização cultural engloba a noção de que cada contexto fornece certas sugestões e limitações socioculturais para o indivíduo em desenvolvimento. Entretanto, considera-se o papel ativo do sujeito na interação com os contextos. Esse processo em que o desenvolvimento humano é orientado pela relação entre as sugestões e limitações socioculturais e a interpretação destas pelo sujeito é designado como canalização cultural (Branco \& Valsiner, 1997). Esse conceito se torna especialmente interessante neste trabalho por auxiliar na compreensão de como a escola enquanto contexto de desenvolvimento pode oferecer limitações e/ou sugestões que dificultem ou promovam uma educação democrática dentro da concepção de educação em/para direitos humanos. Sendo assim, o foco se direciona para as interações entre os sujeitos em seus processos de socialização e compartilhamento de significados constituídos e reconstituídos nessas interações. Considerando os objetivos deste trabalho, torna-se necessário discutir mais profundamente as especificidades dos sujeitos que se pretende estudar, as crianças na faixa etária da educação infantil.

\section{Desenvolvimento infantil na abordagem sociocultural construtivista}

Considerando a abordagem aqui adotada, cada ser humano é visto como único e seu desenvolvimento não é previsível e nem determinável, como uma abordagem simplista de ciência psicológica certamente gostaria. Sendo assim, pode parecer estranho generalizar um determinado período desse desenvolvimento, denominá-lo de infância e atribuir a ele características específicas. Entretanto, conforme já abordado, o desenvolvimento humano se dá a partir da significação que o sujeito cria a partir das sugestões e limitações socioculturais em sua interação com o ambiente. Assim, sendo a infância um momento simbólico e relevante para o contexto sociocultural em que vivemos, ela adquire uma materialidade nas relações reais entre os sujeitos pelos processos de internalização/ externalização.

Para compreender o desenvolvimento humano no período da primeira infância é preciso considerar as condições físicas e biológicas das crianças. Assumindo a presença e característica da complexidade interente ao desenvolvimento humano, não se pode estabelecer uma dicotomia entre biológico e social, porque ambos se constituem mutuamente em um processo contínuo e dinâmico, como uma síntese entre opostos em que a tensão nunca é resolvida. O funcionamento mental, por exemplo, é constituído por processos mentais elementares derivados do equipamento da espécie, da maturação biológica e da experiência individual da criança com o ambiente físico. É pelos processos sociais imersos na cultura que a criança desenvolve o funcionamento mental superior, e é pelas relações reais entre indivíduos humanos que ela adquire o domínio da linguagem, transformando todas as suas funções mentais (Vygotsky, 2000). A maturação biológica, como mero acúmulo quantitativo, não define base para o desenvolvimento de funções superiores, porém não deve ser desconsiderada porque influencia a maneira como o indivíduo se relaciona com o mundo.

No contexto escolar, são os adultos - sejam eles professores e coordenadores da escola ou mesmo governantes e gestores normatizadores da Educação Infantil - que organizam o ambiente de acordo com seus objetivos e crenças em relação às crianças, manipulando os elementos da cultura e promovendo, assim, uma canalização cultural. Ainda que o ambiente seja organizado pelos adultos, existe uma ação das crianças na medida em que significam ativamente as mensagens que lhes são enviadas pelos adultos. Assim, a criança entra em contato com os significados 
da cultura coletiva, composta por sugestões sociais com que ela lida por meio das estruturas e dinâmicas psicológicas que já desenvolveu. Entretanto, enquanto ela lida com essas mensagens da cultura coletiva, não as recebe sem uma elaboração pessoal, mas sim age de maneira ativa e singular de modo a significar essas mensagens a partir da sua experiência com a cultura coletiva. Dessa forma, elabora a sua cultura pessoal a partir da ressignificação das mensagens com que teve contato e depois as transmite às outras pessoas, mais uma vez reconstruindo esses significados. Esses processos de internalização e externalização ativos das crianças em relação ao que lhes é sugerido, ou até imposto culturalmente pelos adultos ou outras crianças, garantem a especificidade do desenvolvimento de cada sujeito (Barreto, 2004; Tacca \& Branco, 2008).

Queiroz, Maciel e Branco (2006) enfatizam o papel da brincadeira nesse processo de assimilação e negação das sugestões ou limitações oferecidas pelas mensagens das pessoas e objetos com que a criança interage. Por meio do brincar, a criança tem a capacidade de extrapolar tanto a affordance (ou "sugestões embutidas no objeto", termo utilizado por Gibson) proposta pelo brinquedo, transformando-o em qualquer objeto que queira ou utilizando-o de múltiplas formas, quanto ao espaço e ao tempo da brincadeira. Assim, a criança pode brincar com essas diversas mensagens culturais, ressignificando-as. Nesse movimento, a criança tanto se desenvolve e aprende os significados da cultura coletiva, constituindo a sua cultura pessoal, quanto é capaz de construir novos significados que vão enriquecer a cultura coletiva. As autoras ressaltam, assim, a importância da valorização da brincadeira no contexto educativo, dada a sua capacidade de promover o desenvolvimento infantil. Apontam, portanto, a necessidade dos educadores estudarem as possibilidades do brincar, de forma a utilizar a brincadeira como importante prática pedagógica.

Essa proposta nos remete à necessidade de compreender os projetos educacionais como fundamentais, na nossa cultura, para o desenvolvimento infantil. Para isso, faremos um breve levantamento histórico da educação infantil no Brasil.

\section{Educação Infantil no contexto brasileiro}

A Educação Infantil se desenvolveu no Brasil, a partir do início do século XX, marcada pela visão assistencialista de trabalho beneficente para atender às classes mais pobres. Decorre desse fato a frequente vinculação das creches, voltadas para a faixa de 0 a 3 anos, a associações filantrópicas ou órgãos de assistência e bem-estar social. Já os Jardins de Infância e préescolas, para crianças de 4 a 6 anos, apesar de frequentemente oferecidos por associações filantrópicas, faziam parte dos sistemas educacionais. (Corrêa, 2007).

Didonet (2001) enfatiza também o fato de as creches estarem historicamente atreladas à inserção das mulheres no mercado de trabalho. Inicialmente, as creches realizavam somente cuidados físicos e de higiene, já que eram apenas um lugar para as crianças ficarem enquanto suas mães estavam no trabalho. Não havia um projeto educativo voltado para as suas necessidades de desenvolvimento. As mudanças na estrutura social, principalmente em relação às conquistas pelas mulheres de novos espaços sociais, fizeram com que as crianças fossem cada vez mais cedo para as creches (Didonet, 2001).

Ainda segundo esse autor, as políticas de Estado para a infância começaram a ser criadas na década de 1940, a partir da mudança na concepção dessas crianças como sujeitos de educação, e pela superação da culpabilização das mães que não ficavam com seus filhos para poder trabalhar. Assim, as creches começaram a englobar projetos educacionais voltados para as crianças como pessoas em desenvolvimento a partir do momento em que não mais serviam apenas como assistência às classes mais pobres, mas sim como uma complementação à educação familiar (Didonet, 2001).

Por volta dos anos 1970, houve uma expansão da oferta de vagas para crianças nessa faixa etária voltada principalmente para as camadas populares (Barreto, 2004). Com a Constituição Federal de 1988, marcada por um movimento da sociedade civil em favor desse atendimento e por discussões teóricas acerca do papel de projetos educacionais para essa faixa etária, a Educação Infantil passou a ser reconhecida como direito de todos e dever do Estado e a ter a sua qualidade avaliada pelo Poder Público. Apesar dos grandes ganhos, porém, ainda se faz necessária uma constante mobilização para que a lei se efetive na prática (Corrêa, 2007).

Dentro do contexto de uma sociedade que cada dia mais privilegia o cognitivo, as pré-escolas surgiram como uma preparação para o Ensino Fundamental, em oposição à creche como local de cuidados físicos e higiene. O desenvolvimento intelectual passou a ser valorizado mesmo nas crianças mais novas, porém numa perspectiva do vir-a-ser, uma preparação para o futuro. Passaram a existir projetos educativos voltados para uma preparação para a próxima etapa escolar, sem considerar as necessidades específicas dessa faixa etária em termos de desenvolvimento global (Didonet, 2001).

Em 1996, a Lei de Diretrizes e Bases da Educação (LDB) trouxe uma nova concepção de Educação Infantil, diversa daquela de pré-escola. Nessa lei, a criança é vista como um sujeito integrado, total, constituído não mais apenas de cognição, mas também de afeto, expressão, movimento e linguagem. O objetivo da Educação Infantil, de acordo com essa lei, passa a ser o desenvolvimento da criança em todos esses aspectos, de forma integrada (Didonet, 2001). Um outro aspecto da LDB ressaltado por Corrêa (2007) como essencialmente importante para a educação brasileira é a incorporação da educação infantil como primeira etapa da educação básica, seguida dos Ensinos Fundamental e Médio. Assim, a educação infantil passa a fazer parte do sistema regular de ensino, garantindo a sua normatização e fiscalização.

Uma mudança mais recente na legislação concernente à Educação Infantil foi implementada pela Lei 11.114, de 16 de maio de 2005. A partir dessa lei, foi modificado o ano de entrada no Ensino Fundamental para os seis anos de idade, reduzindo a Educação Infantil para 0 a 5 anos, e modificando o Ensino Fundamental de oito para nove anos de duração. Conforme aponta Corrêa (2007), essa alteração ainda tem encontrado dificuldades para ser implementada nas escolas brasileiras e tem gerado preocupações de várias ordens. Por ser muito recente e ainda não totalmente implementada, é necessário esperar para observar os seus impactos sobre a qualidade da Educação 
Infantil.

Conforme pode ser observado no breve histórico da constituição da Educação Infantil no Brasil, os modelos de educação são modificados de acordo com a organização social, com a concepção de criança e com os objetivos educacionais da sociedade em cada momento histórico. Na sociedade atual, a criança de zero a cinco anos já é considerada um sujeito de educação, com necessidade de um atendimento que integre tanto as demandas de cuidado e higiene, quanto de um projeto educativo voltado para as peculiaridades desse período de desenvolvimento. Entretanto, como o processo histórico não é linear, as concepções relatadas neste histórico coexistem ainda hoje em algumas instituições de educação infantil, apesar da LDB e da atual visão social um pouco mais generalizada de necessidade de qualidade da educação infantil.

\section{Educação em/para direitos humanos e democracia}

Atualmente, a legislação que trata da educação brasileira tem se voltado para a questão dos Direitos Humanos a partir de todo um cenário internacional de mobilização para a efetivação da Declaração Universal dos Direitos Humanos (DUDH) de 1948, que completou 60 anos recentemente. Um dos documentos decorrentes dessa mobilização é o Plano Nacional de Educação em Direitos Humanos (PNEDH), criado em 2003 a partir de diversos acordos internacionais e legislações nacionais, dentre os quais ressaltamos a Convenção sobre os Direitos da Criança de 1989 e o Estatuto da Criança e do Adolescente (Lei Federal $\mathrm{n}^{\circ}$ 8.069/1990). A partir do PNEDH, vários programas e projetos foram criados para formar educadores e gestores do sistema de ensino e sensibilizá-los na construção de ações de e para os direitos humanos (Zenaide, 2007).

A implementação da Educação em/para os Direitos Humanos (EDH) perpassa por um movimento de afirmação do direito de todos à educação e por uma denúncia às suas violações. A mera criação de instrumentos de lei não garante a transformação das leis em práticas cotidianas. Dessa forma, esse movimento precisa ser contínuo e diário, a fim de garantir a sua efetivação:

A garantia do direito à educação, enquanto direito humano fundamental, percorre um caminho marcado por inúmeros sujeitos sociais: pelas lutas que afirmam esse direito, pela responsabilidade do Estado em prover os meios necessários à sua concretização e pela adoção de concepção de uma educação cujo princípio de igualdade contemple o necessário respeito à tolerância à diversidade (Dias, 2007, p. 454).

A discussão do respeito aos direitos humanos, mais especificamente o direito à educação, passa por um movimento constante do universal ao individual, já que não é possível garantir a igualdade sem tolerância à diferença. Essa concepção, levada ao cotidiano escolar, exige a criação de um espaço de diálogo, em que o respeito e a escuta ao outro são fundamentais. As relações dentro da escola precisam ser horizontais e considerar a construção de saberes a partir da contextualização e problematização da realidade dos vários atores que compõem o espaço escolar. É necessário promover práticas educativas de socialização para a construção de uma sociedade em que todos tenham os seus direitos respeitados. Assim, no bojo da noção de EDH, destaca-se o ideal de democracia (Dias, 2007).

Candau (2007) enfatiza a importância do cuidado com os conceitos no campo dos direitos humanos, caracterizado por uma forte polissemia. Essa autora destaca dois enfoques principais. O primeiro é marcado pela ideologia neoliberal, que visa melhorias à sociedade sem seu questionamento nem transformação do modelo vigente. Enfatiza os direitos humanos em relação aos direitos individuais, civis e políticos, estes vistos como a participação nas eleições, ou seja, a reafirmação da democracia representativa e o distanciamento da prática política cotidiana. Em relação à educação, tem por objetivo formar sujeitos economicamente úteis e politicamente dóceis. Encontra seu aporte teórico na pedagogia construtivista. De forma diametralmente oposta, o segundo enfoque é marcado por um questionamento da organização social e por uma perspectiva dialética. Este visa empoderar os sujeitos e transformar o modelo social vigente. Em relação aos direitos humanos, a ênfase fica nos direitos sociais e econômicos para que os civis e políticos sejam viáveis, valorizando uma participação ativa dos cidadãos e a construção da democracia no cotidiano. No plano educacional, privilegia a interdisciplinaridade para a promoção de uma visão crítica sobre a construção de conhecimento e busca implementar essas práticas educacionais por meio de uma pedagogia crítica fundamentada no construtivismo sociocultural (Candau, 2007).

Congruente com esse segundo enfoque, enfatizamos o conceito de democracia como a participação de todos os sujeitos implicados e a garantia de voz pela constituição de espaços de diálogo. O essencial não é o voto, ou seja, a sondagem do desejo da maioria e posterior imposição desse desejo à minoria, mas sim a negociação pela escuta, acolhimento e reconhecimento do outro e de suas diferenças, a co-construção de práticas e decisões. Nesse contexto a socialização, enquanto co-construção de significados socialmente difundidos, e a comunicação, como principal ferramenta humana de interação com o mundo, tornamse fundamentais para a compreensão das relações democráticas.

\section{Associação Pró-Educação: análise de uma experiên- cia participativa na educação infantil}

Neste trabalho buscou-se analisar uma experiência de trabalho da primeira autora como psicóloga escolar em uma instituição de educação infantil do Plano Piloto. Essa Associação Pró-educação tem 27 anos de existência e surgiu a partir da insatisfação dos pais com o sistema de educação mais tradicional de Brasília, se propondo a ser um espaço de formação não só de crianças, mas de pais e dos profissionais que nela trabalham (Pulino, 2001b). O espaço físico constitui-se de seis salas de aula, sala de coordenação e administração, cozinha, pátio coberto, parque de areia e área verde com muitas árvores e uma horta. São seis turmas no período da manhã e cinco no período da tarde. As turmas são chamadas de Ciclos 1 a 5 , sendo que a primeira abrange as crianças a partir de um ano e oito meses e a última é formada por crianças entre seis e sete anos. Cada ciclo tem no máximo dezesseis alunos e dois professores, ou um professor e um estagiário. A Coordenação é composta por uma coordenadora pedagógica e uma psicóloga escolar. A Diretoria é composta por um grupo de pais e professores eleitos pela Associação. Há ainda 
alguns outros grupos eleitos, denominados instâncias, que são consultados pela Diretoria a fim de auxiliar nas deliberações, e comissões, que são criadas para executar melhorias na infraestrutura ou solucionar problemas cotidianos.

Essa experiência se deu por um período de pouco mais de um ano de atuação profissional da primeira autora como psicóloga escolar da Associação (de 2007 a 2008). Sendo assim, este trabalho consiste em uma pesquisa participante onde a abordagem etnográfica foi empregada como forma de inserção no cotidiano escolar e de investigação em uma relação contínua da pesquisadora com os participantes. Segundo Sato e Souza (2001), essa abordagem tem por objetivo "compreender como as pessoas coletivamente constroem e dinamizam processos sociais, como a subjetividade se expressa, como atribuem significado às situações sociais que ganharam uma organização formalmente constituída" (p. 29). Esse estar no campo de pesquisa permite compreender a vida diária na escola e as redes de relações entre os vários atores desse contexto, com objetivo de estabelecer vínculo de confiança a fim de criar possibilidade de escuta e dar voz aos sujeitos envolvidos. A participação cotidiana permite compreender de forma aprofundada os conflitos e contradições que surgem, repensando as relações hierárquicas e buscando uma contextualização sócio-histórica dos fenômenos escolares. A metodologia se constrói no cotidiano, uma vez que a troca de ideias promove mudanças de atuação frente às dificuldades relacionais (Souza, 1997). É, portanto, a abordagem a ideal para o trabalho do psicólogo escolar por contribuir para o questionamento das ideologias naturalizantes e dos discursos institucionalizados e cristalizados, além de permitir inovações pedagógicas por meio da reflexão e do diálogo (Yokoy \& Pedroza, 2005). Dessa forma, a pesquisadora foi considerada também como participante da pesquisa, junto com as 32 pessoas que atuavam na escola (coordenação, professores, estagiários, administração e equipe de apoio), as 140 crianças, e aproximadamente os 300 pais, mães ou responsáveis.

\section{A instituição, seus objetivos e práticas}

A estrutura associativa da instituição estudada lhe conferiu uma característica muito peculiar e interessante para os objetivos deste trabalho. Existe espaço para a participação ativa de todos os membros da escola em todas as instâncias decisórias, sem deixar, porém, de considerar as suas especificidades. Cada pessoa na escola tem seu nome valorizado por todos, que se esforçam por aprender logo os nomes dos recém-chegados, sejam eles crianças, professores, pais, funcionários ou coordenadores. Assim, cada sujeito é valorizado em sua singularidade e em sua história. Vaise criando uma comunidade que se conhece, se relaciona, se gosta e também entra em conflito nos vários debates nas assembléias e demais instâncias de participação (Pulino, 2001a).

Essa dimensão afetiva da construção de uma comunidade é muito interessante do ponto de vista do psicólogo escolar em sua atuação como mediador das relações interpessoais. Esses vários sujeitos, com suas opiniões, idiossincrasias e histórias de vida, entram nesse espaço democrático trazendo consigo uma série de expectativas e projetos quanto à educação dos seus filhos. Na medida em que vão se inserindo no grupo, o modificam e também são modificados por ele. É pelo diálogo, pela negociação cotidiana, que as decisões vão sendo tomadas e assim acontece a gestão escolar com a participação de todos os sujeitos (Pulino, 2001b).

Apesar disso, esse é também um campo de contradições. Muitas vezes, essas relações acolhedoras se transformam em grandes atritos. $\mathrm{O}$ debate democrático é sempre perpassado por falas passionais, e é visível como as relações interpessoais afetam a tomada de decisão. Por isso, a construção democrática precisa ser feita no cotidiano sempre através da promoção de reflexões a respeito dos conflitos que surgem (Dias, 2007).

Esse ideal de democracia como negociação, porém, não é constantemente observado. O movimento dinâmico do desenvolvimento humano marca profundamente os debates. Há períodos de consenso, alcançado através de um rico diálogo e negociação, pela construção de um espaço em que todos são respeitados em suas singularidades e suas contribuições são ouvidas a fim de aproveitar a riqueza da construção coletiva das decisões. Entretanto, as contradições presentes em uma sociedade excludente e individualista fazem parte desse contexto da mesma forma. Portanto, há também momentos em que as Assembléias são marcadas por desavenças, e o processo de construção coletiva de decisões acaba sendo transformado em luta de interesses pessoais.

O psicólogo escolar atua diretamente nessas relações interpessoais, buscando apontar essas contradições e refletir sobre elas. O objetivo não é evitar esses conflitos, mas aproveitálos no que trazem de riqueza para o desenvolvimento de todos os sujeitos envolvidos. Nos vários espaços de discussão, a intenção é sempre propiciar um diálogo em que seja garantido o direito de voz a todos os participantes e que não haja apenas a construção da imposição de voto da maioria, mas sim o respeito ao direito de todos. Vale ressaltar que o psicólogo, como membro dessa comunidade, também se afeta por esses conflitos, uma vez que participa da vida diária da escola de forma plena. Para isso, é necessária uma formação pessoal desse profissional para que possa sempre fazer o exercício de se deslocar do contexto para uma compreensão mais ampla, porém sem deixar de ser um membro da comunidade, nem de estabelecer vínculos com os outros. É nesse movimento dinâmico que a pesquisa participante se faz concomitante à prática profissional e ao seu desenvolvimento (Yokoy \& Pedroza, 2005).

Apesar de não participarem das instâncias nem das Assembléias como associadas, as crianças participam do modelo associativo e vivem ativamente a proposta democrática da escola. É preciso considerar que o momento de desenvolvimento das crianças não é o mesmo dos adultos e, considerando as suas diferenças, não seria possível tratar a sua participação de uma maneira igual. Entretanto, o seu direito de participação e de voz é garantido pelas práticas pedagógicas.

A escola não possui um Projeto Político Pedagógico formalmente registrado em papel. Apesar disso, a sua produção escrita é vasta: duas revistas com artigos de professores, coordenadores e pais a respeito do projeto e prática pedagógica; textos escritos eventualmente por professores e, principalmente, por coordenadores para momentos de formação ou para comunicações aos pais; relatórios produzidos bimestralmente pelos professores sobre o desenvolvimento de cada criança e o 
projeto educativo do período em questão; além de uma série de artigos, dissertações e teses produzidos a partir das inúmeras pesquisas realizadas no contexto da escola. Todos esses textos contribuem para uma consolidação da prática pedagógica e para um registro histórico de suas propostas e mudanças por que passa. São produzidos e utilizados pelos associados em seus momentos de formação e estudos, sempre com uma perspectiva crítica e uma visão de que cada momento traz novos desafios, por isso a escola precisa mudar para continuar sendo a mesma. Assim, essa consolidação não é estagnante do processo dinâmico de construção cotidiana do projeto pedagógico pelos sujeitos que participam da escola.

Existe também uma forte valorização na escola da comunicação oral e da possibilidade que esta traz de uma certa permanência da sua identidade. Mais uma vez aqui, dá-se o processo dialético de desenvolvimento: essa comunicação tanto realiza um constante processo de resgate da história da Associação, quanto traz novas propostas que provocam mudanças. Nesse desenvolvimento, constantemente os associados se opõem ou apóiam tanto a mudança quanto a permanência de certas práticas. Nos vários espaços de diálogo, desde as conversas informais nos corredores da escola até os momentos de discussões polêmicas em Assembléia, essas posições são utilizadas no jogo político da negociação democrática. É frequente ouvir dos associados "isso é um absurdo, no meu tempo não era assim... Desse jeito essa escola vai perder a sua identidade" ou "o mundo muda e é preciso que a gente aprenda com os novos desafios de cada momento".

Apesar desse constante movimento entre mudança e permanência, entre registrar o projeto político pedagógico através de textos diversos e contestar o seu registro por medo da estagnação, é possível dizer que existe um projeto político pedagógico nessa escola, que se materializa nesse movimento dos diálogos e práticas cotidianas. Assim, utilizaremos alguns exemplos das práticas educacionais, especificamente aquelas voltados à construção de regras limites no cotidiano de sala de aula, para ilustrar como as crianças participam ativamente do processo democrático e têm espaço garantido para expressar as suas ideias e modificar esse projeto.

\section{Rotina, atividades e limites contextualizados}

A rotina na escola é composta por uma constante alternância entre a sala e os espaços abertos da escola. Contrapõe-se à visão de disciplinarização das crianças porque busca, nesse movimento, englobar as necessidades dessa faixa etária tendo em vista o seu desenvolvimento global, o que exige versatilidade e criatividade nas atividades pedagógicas e, principalmente, a necessidade da criança dar sentido a cada momento do dia. Além disso, a compreensão espaço-temporal (habilidade muito importante para o desenvolvimento cognitivo ou mesmo afetivo) vai sendo internalizada pela criança que pode, assim, prever quais serão as próximas atividades e como se dará o desenrolar das atividades do dia. Essa ferramenta auxilia a construção de um projeto pedagógico em que as crianças não são meros objetos da educação, mas sim sujeitos. As atividades sempre acontecem com um sentido compartilhado pelas crianças, já que sabem o planejamento do dia.

A rotina também permite uma maior contextualização dos limites. Quando o professor vai explicar o porquê de determinada atividade acontecer em determinado momento, ele não recorre a explicações baseadas na sua vontade pessoal ("porque eu quero fazer isso agora"), mas sim no desenrolar das atividades do dia ("porque agora é hora disso"). É claro que o interesse das crianças pelas atividades é sempre levado em conta, porém não se pode deixar de afirmar que os limites são extremamente importantes para o desenvolvimento infantil, na medida em que provêm segurança, reconhecimento do outro e da organização social, entre outras razões. Sendo assim, estabelecer os limites de uma maneira contextualizada promove a autonomia e o respeito aos interesses das crianças, sem, no entanto, cair no laissez-faire.

Outra característica que se destaca é o momento do parque: primeiro pela duração de uma hora, que proporciona às crianças liberdade para escolher e comandar as suas atividades (os professores apenas as acompanham para cuidar de sua segurança e intervir nos conflitos); segundo, pela característica física da escola ter uma grande área verde, com árvores frutíferas nas quais as crianças são estimuladas a subir e um parque de areia; e ainda pelo fato de as crianças de todas as turmas (de 2 a 7 anos) partilharem o mesmo espaço juntas. Esse é um momento muito rico em que as crianças interagem livremente, podem escolher as suas brincadeiras, inclusive com crianças de outras salas e têm espaço amplo para aproveitar a natureza.

Retomando o conceito de Zona de Desenvolvimento Proximal, proposto por Vygotsky (2000), é necessário criar espaços de socialização nas escolas de crianças em faixas diferentes de desenvolvimento para que, na sua interação por meio da brincadeira, sejam criadas zonas que estimulem o seu desenvolvimento. Essa diversidade de faixas etárias e possibilidades de interação pela liberdade do espaço do parque promove um efetivo espaço de socialização em que, por meio dos processos de comunicação, as crianças podem agir ativamente sobre os significados da cultura modificando a si, umas às outras e a cultura. Nesse jogo coletivo, aprendem a dividir o espaço e a negociar os seus desejos, construindo um espaço efetivamente público.

\section{"Não gostei": a negociação}

O "não gostei” é uma expressão muito ouvida nessa escola. O seu uso é incentivado nos casos de conflitos entre as crianças, utilizado principalmente pelos professores na mediação desses conflitos, estimulando o desenvolvimento da linguagem como recurso de negociação. Por exemplo, quando uma criança é agredida, o educador age no sentido de promover uma discussão sobre o conflito que ocorreu entre os envolvidos. A intenção é de que a criança agredida, por meio dessa expressão, demonstre a sua insatisfação com a agressão do colega e, dessa forma, aprenda a resolver os seus conflitos de maneira autônoma, por meio do diálogo. O colega, por sua vez, é levado a reconhecer a insatisfação por ele provocada, num movimento indutivo de reconhecimento do outro, que tem desejos e opiniões diferentes das suas. O objetivo é favorecer que, nesse momento, se estabeleça um processo de desenvolvimento do conceito de "eu" a partir do reconhecimento pleno e da diferenciação em relação ao outro. É nessa negociação dos desejos e opiniões que as crianças vão percebendo que os seres humanos vivem 
necessariamente em sociedade e, para tal, precisam aprender a se respeitar.

Essa intervenção pedagógica é coerente com a abordagem sociocultural construtivista do desenvolvimento por valorizar o conflito como promotor do desenvolvimento (Madureira \& Branco, 2005). Cada uma dessas negociações permite a troca de conhecimentos e significados construídos nas interações entre os indivíduos. Assim, as crianças têm a oportunidade de partilhar as suas concepções de mundo e apreender e ressignificar as mensagens culturais.

É importante ressaltar que a intervenção do professor vai além da comunicação, com uma grande preocupação em relação à metacomunicação. Quando vai fazer uma intervenção do "não gostei", o educador se abaixa para ficar da altura da criança, olha para ela com calma e tenta conversar de uma maneira acolhedora. Aliás, essa postura é comum não só nesse tipo de intervenção. Nessa escola, a criança é vista como uma pessoa que tem suas opiniões e contribuições para o cotidiano escolar. Essa é uma prática baseada na concepção de coerência que se tem, e que é aqui defendida, da necessidade de coerência entre o processo político e o pedagógico. Uma escola não se pode considerar participativa nem democrática se essas características não forem vistas como objetivos para todos os âmbitos e atores do contexto escolar. Conforme Perrenoud (2004) nos demonstra, a educação para a cidadania não pode estar só no projeto, ou nos livros, ou em objetivos impostos aos alunos. Ela precisa ser construída nas interações entre os indivíduos envolvidos.

Retomando o conceito de metacomunicação (Pires \& Branco, 2007), essa preocupação dos professores em realizar uma intervenção que não se foque apenas no plano verbal, mas que se atente também para a postura, o tom de voz, o gestual e a maneira de acolher a criança é fundamental para contextualizar e direcionar a interpretação dos significados que são co-construídos nos processos de comunicação na interação em questão.

O professor precisa, portanto, ser muito bem formado, e o psicólogo atua, juntamente com a equipe pedagógica, diretamente na sua formação continuada. Os espaços de reunião da equipe são também marcados pela organização democrática em que é necessário respeitar o direito de participação de todos. Entretanto, isso não significa que todos participem de maneira igual. É necessário sempre pensar as peculiaridades de cada pessoa e a sua função enquanto profissional da Associação. Dessa forma, a coordenação assume um papel de autoridade, buscando, assim como o professor em sala de aula com os seus alunos, uma organização do ambiente que promova o desenvolvimento dos professores para uma melhoria da qualidade do ensino. Essa relação entre professores e coordenação também é dinâmica e oscilante. Às vezes, assume características mais patronais e outras, de acolhimento e superproteção. Assim, as discussões do grupo, aliadas a uma necessidade constante de reflexão sobre a prática profissional, são extremamente necessárias para o desenvolvimento de todos.

A partir desses resultados, fica evidente o papel que a organização democrática tem no desenvolvimento da Associação. Ao mesmo tempo em que implementar essas práticas de construção coletiva das decisões demanda muito esforço de todos e parece sempre beirar o colapso, é exatamente a reflexão do grupo que traz uma crítica e uma possibilidade de resolução de conflitos. Sendo assim, o ideal de democracia participativa precisa ser sempre reafirmado, ressignificado e reinventado nas relações entre os indivíduos.

\section{"Combinados": a construção ativa e cotidiana de regras}

Retomando as práticas pedagógicas coerentes com as propostas de educação em/para direitos humanos das crianças, outra intervenção integrante do projeto pedagógico no que tange à construção dos limites é a dos “combinados”. Nessa escola, não existe uma cartilha de regras pré-determinadas de convivência para as crianças. As regras são construídas no cotidiano de sala de aula, pelo grupo, a partir dos conflitos que acontecem. Se a intervenção do "não gostei” promove uma reflexão mais pontual sobre os conflitos das crianças, eles podem ser sempre levados para as rodas de discussão em sala para que todo o grupo possa aproveitar esse conflito para construir uma regra necessária para si. As regras são construídas junto com as crianças, com a sua colaboração e participação ativa. Assim, não lhes são impostas, porque elas entendem o seu sentido e função na organização daquele grupo específico. Cada turma faz os seus combinados, os escreve ou desenha, e os coloca na parede para que possam ser sempre vistos e revistos por todos. Esse trabalho é feito diversas vezes ao longo do ano porque, com o passar do tempo, as regras precisam ser mudadas, relembradas ou mesmo descartadas.

Essa participação ativa na construção dos limites permite à criança uma compreensão e apropriação dos significados de cada uma dessas regras para a organização daquele grupo social. Assim, podem compreender de uma maneira muito mais concreta a escolha dos seres humanos de vida em sociedade e consequente necessidade de organização dessa vida por meio de negociações e concessões.

A noção de combinados também é presente no âmbito da gestão escolar pelos associados. Os associados não parecem perceber a organização da escola como estática nem as regras como perpétuas, e sempre se manifestam no sentido de rever regras antigas ou propor novas. Dadas as características e necessidade de cada faixa do desenvolvimento, a construção das regras pelos adultos não ocorre da mesma maneira que das crianças. Os adultos tendem a perpetuar mais as suas elaborações, construir documentos com as regras feitas e cobrar de maneira mais enfática a sua realização no dia-a-dia.

A construção de regras que fazem sentido aos cidadãos é fundamental para a democracia. Em nossa sociedade, somos acostumados a delegar o nosso poder decisório a um representante e não participar da organização da sociedade, mas sim receber as regras na forma de leis que nos são impostas. Os sujeitos desse contexto escolar participam de um processo chamado por Candau (2008) de empoderamento. A partir da prática e vivência de uma experiência de democracia participativa, esses sujeitos podem perceber o seu poder de decisão em outros âmbitos da sociedade e desencadear uma efetiva transformação social. Essa é realmente uma educação para a cidadania, que forma indivíduos capazes de realizar uma leitura crítica das organizações sociais, agir de forma a exigir os seus direitos e respeitar os direitos de seus pares, 
reconhecendo e respeitando o outro em sua singularidade, com vistas a promover a construção de uma coletividade mais justa para todos (Dias, 2007).

\section{Considerações Finais}

A educação em/para os direitos humanos se baseia necessariamente na garantia do direito à educação de qualidade para todos (Dias, 2007). Uma questão que fica neste trabalho, portanto, é o fato da escola em questão ser uma Associação e não uma instituição pública de ensino. Dessa forma, não é acessível a uma considerável parcela da população. Apesar da qualidade do seu projeto pedagógico, ainda recai na crítica de Corrêa (2007) de que a educação infantil no Brasil se polariza em projetos educacionais inovadores para as classes mais favorecidas e projetos de baixa qualidade para as camadas mais pobres da população.

Sendo assim, esse é um modelo educacional muito interessante para ser estudado a fim de que possa gerar ideias e subsídios não apenas para o seu aperfeiçoamento, mas, principalmente, contribuir para a construção de novas propostas para a educação nas escolas públicas do País. A discussão de uma educação em/para os direitos humanos deve destacar a necessidade da mobilização da sociedade para a implementação, de fato, de gestões democráticas nas escolas públicas brasileiras. É preciso superar o modelo neoliberal de gestão "democrática" que tem por objetivo diminuir a responsabilidade do Estado, buscando reduzir seus investimentos e/ou reparti-los com a iniciativa privada, o que limita a real autonomia das escolas por meio da ampliação da regulação, do controle e da avaliação (Fonseca, 2003).

Ao Estado cabe educar prioritariamente a população brasileira para a cidadania e para a democracia, levando a todos não apenas o conhecimento de seus direitos, mas a aprendizagem e desenvolvimento de práticas cidadãs. Sendo assim, ressaltase aqui a necessidade de mais trabalhos sobre a importância da gestão democrática para a educação em/para direitos humanos a fim de embasar futuras políticas públicas.

\section{Referências Bibliográficas}

Barreto, A. M. (2004). Educação infantil: crenças e valores sobre as relações entre práticas pedagógicas especificas e o desenvolvimento da criança (Tese de doutorado, Universidade de Brasília, Brasília).

Branco, A. U. (2003). Social development in social contexts: cooperative and competitive interaction patterns in peer interactions. In J. Valsiner \& K. J. Connolly (Orgs.), Handbook of developmental psychology (pp. 238-256). London: Sage.

Branco, A. U., \& Valsiner, J. (1997). Changing methodologies: a co-constructivis study of goal orientations in social interactions. Psychology and Developing Societies, 9(1), 35-64.

Candau, V. M. (2007). Educação em direitos humanos: desafios atuais. In R. M. G. Silveira, A. A. Dias, L. F. G. Ferreira, M. L. P. A. M. Feitosa, \& M. N T. Zenaide (Orgs.), Educação em direitos humanos: fundamentos teóricometodológicos (pp. 399-412). João Pessoa: Editora Universitária.

Candau, V. M. (2008). Direitos humanos, educação e interculturalidade: as tensões entre igualdade e diferença. Revista Brasileira de Educação, 13(37), 45-56.

Carvalho, J. S., Sesti, A. P., Andrade, J. P., Santos, L. S., \& Tibério, W. (2004).
Formação de professores e educação em direitos humanos e cidadania: dos conceitos às ações. Educação e Pesquisa, 30(3), 435-445.

Comitê Nacional de Educação em Direitos Humanos. (2006). Plano Nacional de Educação em Direitos Humanos. Brasília, DF: Secretaria Especial dos Direitos Humanos.

Corrêa, B. C. (2007). A educação infantil. In R. P. Oliveira \& T. Adrião (Orgs.), Organização do ensino no Brasil: níveis e modalidades na Constituição Federal e na $L D B$ (pp. 13-30). São Paulo: Xamã.

Dias, A. A. (2007). Da educação como direito humano aos direitos humanos como princípio educativo. In R. M. G. Silveira, A. A. Dias, L. F. G. Ferreira, M. L. P. A. M. Feitosa, \& M. N. T. Zenaide (Orgs.), Educação em direitos humanos: fundamentos teórico-metodológicos (pp. 441-456). João Pessoa: Editora Universitária.

Didonet, V. (2001). Creche: a que veio... para onde vai... Em Aberto, 18(73), 11-17.

Fonseca, M. (2003). Projeto político pedagógico e o Plano de Desenvolvimento da Escola: duas concepções antagônicas de gestão escolar. Cadernos do CEDES, 23, 302-318

Lei n. 8.069, de 13 de julho de 1990. (1990, 13 de julho). Dispõe sobre o Estatuto da Criança e do Adolescente e dá outras providências. Brasília, DF: Presidência da República.

Lei n. 9.394, de 20 de dezembro de 1996. (1996, 23 de dezembro). Estabelece as Diretrizes e Bases da Educação Nacional. Diário Oficial da União, seção 1.

Lei n. 11.114, de 16 de maio de 2005. (2005, 16 de maio). Altera os arts. $6^{\circ}, 30$, 32 e 87 da Lei n. 9.394, de 20 de dezembro de 1996, com o objetivo de tornar obrigatório o início do ensino fundamental aos seis anos de idade. Brasília, DF: Presidência da República.

Madureira, A. F. A., \& Branco, A. U. (2005). Construindo com o outro: uma perspectiva sociocultural construtivista do desenvolvimento humano. In M. A. Dessen \& A. L. Costa Júnior (Orgs.), A ciência do desenvolvimento humano: tendências atuais e perspectivas futuras (pp. 90-109). Porto Alegre: Artes Médicas

Martins, L., \& Branco, A. U. (2001). Desenvolvimento moral: considerações teóricas a partir de uma perspectiva sociocultural construtivista. Psicologia: Teoria e Pesquisa, 17(2), 169-177.

Organização das Nações Unidas. (1989). Convenção sobre os Direitos da Criança. Recuperado de http://www.unicef.org/brazil/pt/resources_10120.htm

Palmieri, M. W. A., \& Branco, A. U. (2004). Cooperação, competição e individualismo em uma perspectiva sócio-cultural construtivista. Psicologia Reflexão e Crítica, 17(1), 189-198.

Perrenoud, P. (2004). Escola e cidadania: o papel da escola na formação para a cidadania. Porto Alegre: ArtMed.

Pires, S. F. S., \& Branco, A. U. (2007). Protagonismo infantil: co-construindo significados em meio às práticas sociais. Paidéia, 17(38), 311-320.

Pulino, L. H. C. Z. (2001a). Acolher a criança, educar a criança: uma reflexão. Em Aberto, 18(73), 29-40.

Pulino, L. H. C. Z. (2001b). Gestão democrática da instituição de educação infantil: a experiência da "Vivendo e Aprendendo". Em Aberto, 18(73), 131-135.

Queiroz, N. L. N., Maciel, D. A., \& Branco, A. U. (2006). Brincadeira e desenvolvimento infantil: um olhar sociocultural construtivista. Paidéia, 16(34), 169-179.

Sato, L., \& Souza, M. P. R. (2001). Contribuindo para desvelar a complexidade do cotidiano através da pesquisa etnográfica em psicologia. Psicologia USP, 12(2), 29-47.

Souza, M. P. R. (1997). As contribuições dos estudos etnográficos na compreensão do fracasso escolar no Brasil. In A. M. Machado \& M. P. R. S. Souza (Orgs.), Psicologia Escolar: em busca de novos rumos (pp. 139-156). São Paulo: Casa do Psicólogo.

Tacca, M. C. V. R., \& Branco, A. U. (2008). Processos de significação na relação professor-alunos: uma perspectiva sociocultural construtivista. Estudos de Psicologia, 13(1), 39-48.

Valsiner, J. (1989). The social nature of human development: some preliminaries. 
In J. Valsiner, Human development and culture: the social nature of personality and its study (pp. 1-15). Lexington, MA: Lexington Books. Valsiner, J. (1998). The guided mind. Cambridge, MA: Harvard University Press. Vygotsky, L. S. (2000). A formação social da mente. São Paulo: Martins Fontes. Yokoy, T., \& Pedroza, R. L. S. (2005). Psicologia escolar em educação infantil: reflexões de uma atuação. Psicologia Escolar e Educacional, 9(1), 95-104. Zenaide, M. N. T. (2007). Introdução. In R. M. G. Silveira, A. A. Dias, L. F. G. Ferreira, M. L. P. A. M. Feitosa \& M. N. T. Zenaide (Orgs.), Educação em direitos humanos: fundamentos teórico-metodológicos (pp. 15-25). João Pessoa: Editora Universitária.

Julia Chamusca Chagas, mestre em Processos de Desenvolvimento Humano e Saúde pela Universidade de Brasília, é psicóloga escolar do Programa de Apoio a Pessoas com Necessidades Especiais (PPNE) da Universidade de Brasília. Endereço para correspondência: Campus Universitário Darcy Ribeiro, Asa Norte, Instituto Central de Ciências ICC-Norte BT 678 - Programa de Apoio às Pessoas com Necessidades Especiais (PPNE). Telefones para contato (61) 8102-6574, Fone/Fax (61) 3307-2972. E-mail: juliachagas@unb.br.

Regina Lúcia Sucupira Pedroza, doutora em Psicologia pela Universidade de Brasília e pós-doutora em Sciences de Education pela Université Paris V, é professora Adjunta na Universidade de Brasília. E-mail: rpedroza@unb.br.

Angela Uchoa Branco, doutora em Psicologia pela Universidade de São Paulo e pós-doutora pela University of North Carolina e pela Duke University, é professora Associada 3 na Universidade de Brasília. E-mail: ambranco@terra.com.br. 